Available online at http://jurnal.goretanpena.com/index.php/JSSR

\title{
SIMULASI ALAT PINTU OTOMATIS KERETA API MENGGUNAKAN SENSOR ULTRASONIC BERBASIS MICROCONTROLLER
}

\author{
Dedi Setiawan ${ }^{1}$, Ardianto Pranata ${ }^{2}$, Puji Sari Ramadhan ${ }^{3}$, Azanuddin $^{4}$ \\ STMIK Triguna Dharma, Medan \\ e-mail: ${ }^{1}$ setiawandedi07@gmail.com
}

\begin{abstract}
A train is a form of rail transportation consisting of a series of vehicles towed along a railroad track to transport cargo or passengers. However, there are some remote areas that have not been touched by the government, where accidents often occur at railroad crossings. Therefore, a tool that can minimize the problem of accidents at railroad crossings is designed, namely the train automatic door device, which uses a microcontroller, photodioadamic and infrared sensors, servo motors, buzzers and led lights. With this automatic train door device, it will be able to close the train crossing door at the railroad crossing automatically when a train passes and can open the train door automatically when no train passes. This automatic work system uses Photodiode and Infra RED sensors that are connected to a microcontroller to process trains that pass in the train lane. Then when the object is detected, the sensor then sends a signal to the microcontroller which will then give the ON command to the LED Light and Buzzer as a notification indicator that the train will pass and use a servo motor to close the railroad crossing. Thus, this railroad gate security system can minimize the risk of accidents at railroad crossings.
\end{abstract}

Keywords: Trains, Microcontrollers, Photodio and Infra red Sensors, Servo Motors, Buzzers, and Led Lights

\begin{abstract}
Abstrak: Kereta api adalah bentuk transportasi rel yang terdiri dari serangkaian kendaraan yang ditarik sepanjang jalur kereta api untuk mengangkut kargo atau penumpang. Namun ada beberapa daerah pedalaman yang belum disentuh oleh pemerintah dan sering terjadi kecelakaan di penyebrangan perlintasan kereta api. Oleh sebab itu maka dirancanglah alat yang dapat meminimalisirkan masalah kecelakaan di penyebrangan perlintasan kereta api yaitu alat pintu otomatis kereta api, yang menggunakan microcontroller, sensor photodioada dan Infrared, motor servo, buzzer dan lampu led. Dengan alat pintu otomatis kereta api ini nantinya dapat menutup pintu penyebrangan kereta api di penyebrangan perlintasan kereta api secara otomatis ketika ada kereta api yang lewat dan dapat membuka pintu kereta api tersebut secara otomatis ketika tidak ada kereta api yang lewat. Sistem kerja otomatis ini ini menggunakan sensor Photodioda dan Infra RED yang dihubungkan ke microcontroller agar memproses kereta api yang melintas di lajur kereta api. Kemudian ketika objek terdeteksi maka selanjutnya sensor mengirimkan sinyal ke microcontroller kemudian akan memberikan perintah ON terhadap Lampu LED dan Buzzer sebagai indikator pemberitahuan bahwa kereta api akan melintas serta menggunakan motor servo untuk menutup jalur perlintasan kereta api tersebut. Dengan demikian sistem keamaanan pintu lajur kereta api ini dapat memperkecil resiko terjadinya kecelakaan pada perlintasan kereta api.
\end{abstract}

Kata kunci: Mobile, M-Learning, Android 
Available online at http://jurnal.goretanpena.com/index.php/JSSR

\section{PENDAHULUAN}

Dalam suatu sistem jalan raya, persimpangan merupakan titik terjadinya konflik antara moda transportasi. Suatu persimpangan biasanya terbentuk dari petemuan antara dua ruas jalan dengan arah yang berbeda. Pertemuan antara dua jenis prasarana transportasi jalan raya dengan perlintasan rel kereta api merupakan salah satu bentuk pertemuan yang dapat menimbulkan masalah yaitu kecelakaan dan kemacetan. Hal ini tentunya tidak bisa dihindari karena beberapa jalan utama antar kota ataupun dalam kota bersimpangan dengan jalan rel, dan masing-masing jalan tersebut memiliki peraturan-peraturannya sendiri dengan bermaksud memberikan keamanan dan kenyamanan penggunanya. Pertemuan jalan sebidang ini mempunyai aturan bahwa jalan rel kereta api menjadi prioritas dibandingkan jalan raya, sehingga sering terjadinya penumpukan atrian kendaraan yang panjang. Mengevaluasi dan menganalisis perlintasan sebidang yang berupaya meningkatkan keselamatan pengendara atau pengguna jalan maupun kereta api dengan mengavaluasi kondisi teknis perlintasan sebidang yang berupa kelengkapan infrastruktur, rambu-rambu lalulintas dan perlintasan kereta api serta menganalisis volume lalulintasnya.(Asfiati, Sri Mutiara, 2020)

Namun jika berbicara transportasi darat pada kereta api khususnya di daerah pedalaman yang daerah tersebut belum disentuh oleh Pemerintah, keselamatan dalam bertransportasi tersebut menjadi tugas pemerintah untuh mengevaluasinya dikarenakan sering terjadi kecelakaan tabrakan di penyeberangan perlintasan kereta api yang memakan korban jiwa. Kecelakaan tersebut terjadi karena belum dibangunnya pintu kereta api di kawasan pedalaman tersebut. Berkenaan dengan masalah tabrakan di perlintasan kereta api tersebut mendorong kita khususnya orang - orang yang membidangi ilmu komputer untuk menciptakan alat - alat yang bisa membantu kehidupan orang banyak untuk mengatasi permasalahan yang ada selama ini khususnya di bidang keselamatan transportasi kereta api.

Untuk mengurangi tingkat Kesalahan manusia dalam menjaga pintu perlintasan yang sering terjadi diakibatkan kurangnya rasa tanggung jawab dalam melaksanakan tugas seperti ngantuk atau meninggalkan tempat pada saat bertugas yang akan berakibat fatal jika ini terjadi. Oleh sebab itu diperlukan sebuah alat cerdas yang dapat membantu kerja petugas dalam menjaga pintu perlintasan. Sistem cerdas ini menggunakan microcontroller sebagai IC pengendali.

Menurut Purnomo (2015) bahasa pemrograman untuk mikrokontroler AVR yang paling populer adalah menggunakan bahasa C. Bahasa $\mathrm{C}$ adalah bahasa pemrograman tingkat menengah. Selain bahasa $\mathrm{C}$ ada bahasa tingkat rendah seperti assembly dan bahasa tingkat tinggi seperti basic dan pascal. Semakin rendah bahasa pemrograman maka semakin mendekati kode mesin namun sulit dimengerti oleh manusia. Sebaliknya semakin tinggi bahasa pemrograman maka semakin mudah dimengerti oleh manusia namun sukar untuk diaplikasikan ke mesin, dalam hal ini adalah mikrokontroler.(Mubarok et al., 2018) Rangkaian dasar elektronika yang diterapkan dalam penelitian ini menggunakan inputan sensor photodioda dan infrared sebagai pendeteksi kereta api yang melintas pada jalur perlintasan pintu kereta api.

Sebuah photodioda biasanya mempunyai karakteristik yang lebih baik dari pada phototransistor dalam responya terhadap cahaya infra merah. Photodioda mempunyai respon 100 kali lebih cepat dari pada phototransistor. Sebuah photodioda biasanya dikemas dengan plastik transparan yang juga berfungsi sebagai lensa fresnel. Lensa ini merupakan lensa cembung yang mempunyai sifat mengumpulkan cahaya. 
Available online at http://jurnal.goretanpena.com/index.php/JSSR

Lensa tersebut juga merupakan filter cahaya, lebih dikenal sebagai 'optical filter', yang hanya melewatkan cahaya infra merah saja. Walaupun demikian cahaya yang nampak pun masih bisa mengganggu kerja dari dioda infra merah karena tidak semua cahaya nampak bisa di filter dengan baik. Faktor lain yang juga berpengaruh pada kemampuan penerima infra merah adalah 'active area' dan 'respond time'. (Sadi, 2015).

Sensor Fotodioda dengan penyerap setebal $150 \mathrm{~nm}$ diarsitektur terbalik menunjukkan arus gelap $10 \quad 6$ $\mathrm{A} / \mathrm{cm} 2$ pada bias mundur $2 \mathrm{~V}$ dan EQE di atas $20 \%$ pada panjang gelombang 1440 nm. Pemodelan optik untuk arsitektur iluminasi atas dapat meningkatkan kontaktransparansi hingga $70 \%$. Pendinginan tambahan $(193 \mathrm{~K})$ dapat meningkatkan sensitivitas hingga $60 \mathrm{~dB}$. Tumpukan ini bisa diintegrasikan pada ROIC CMOS, memungkinkan pengurangan biaya urutan besaran untuk sensor inframerah.(Malinowski et al., 2017).

Sebagai rangkaian output peneliti menggunakan motor servo untuk menggerakan palang pintu dan buzzer sebagai indikator suara serta LCD untuk menampilkan text agar para pengendara dan pengguna perlintasan dapat mengetahui keberadaan dari kereta yang akan melintas pada jalur penyeberangan tersebut.

\section{METODE}

Dalam perancangan pintu otomatis kereta api ini, Microcontroller digunakan sebagai komponen utama yang mengatur komponen yang lainnya seperti sensor photodioda dan infrared, Buzzer,LCD dan Motor Servo. Hardware pintu otomatis kereta api ini dirancang agar Microcontroller dapat menerima masukan dari sensor photodioda dan infrared kemudian hasilnya yaitu Buzzer mengeluarkan bunyi dan LCD menampilkan teks untuk memberitahukan kereta melintas, Motor Servo dapat bergerak otomatis sebagai output rangkaian Microcontroller tersebut.

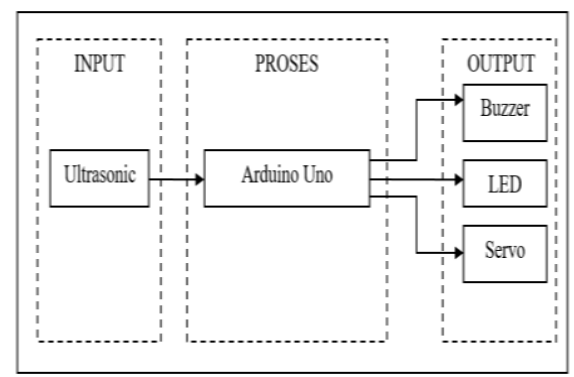

Gambar 1. Blok Diagram

Dari gambar diagram blok diatas pada sensor photodioda dan infrared dapat diuraikan yaitu microcontroller mendapatkan sinyal atau data input dari sensor photodioda dan infrared, setelah itu data input sinyal yang masuk akan diproses lagi di dalam micorontroller, setelah diproses maka didapatkan hasil proses tersebut berupa data output yang akan dikirim ke buzzer, LCD dan motor servo agar buzzer dapat mengeluarkan suara atau bunyi dan motor servo dapat bergerak otomatis sesuai yang sudah diprogramkan.

\section{Algoritma Sistem}

Di sini akan dijelaskan tentang proses yang terjadi pada sistem saat dijalankan. Adapun tahapan - tahapan proses dimulai dari pengkatifan sistem hingga proses penyalaan Buzzer,LED, dan motor servo. Untuk tahapan - tahapan proses dapat dilihat pada gambar 2 .

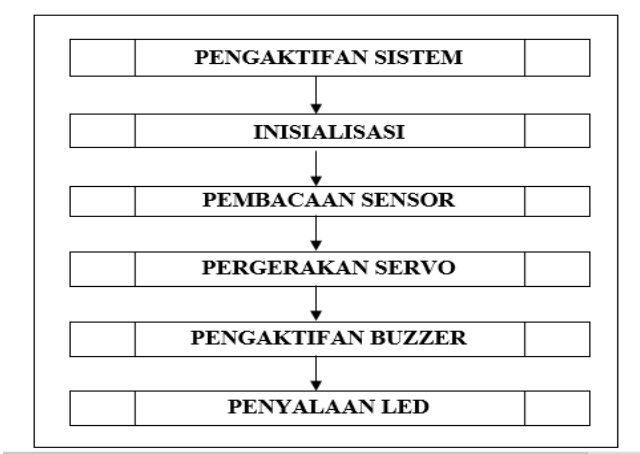

Gambar 2. Tahapan Kerja Sistem

Langkah pertama :

1. Pengaktifan Sistem 
Available online at http://jurnal.goretanpena.com/index.php/JSSR

Merupakan bagian awal dalam mempersiapkan sistem yaitu dengan mengaktifkan komponen input dan komponen output yang sudah terhubung.

2. Insialisasi

Merupakan tahap menginisialisasikan semua komponen sistem yang sudah terhubung.

3. Pembacaan Sensor

Di bagian ini sensor akan bertugas membaca objek yang terdeteksi untuk dijadikan sebagai inputan microcontroller.

4. Pergerakan Servo

Motor Servo akan bergerak ketika sensor membaca objek yang terdekteksi dan motor servo akan kembali ke posisi semula ketika sensor tidak mendeteksi objek.

\section{Pengaktifan Buzzer}

Buzzer akan diaktifkan ketika sensor mendeteksi objek dan buzzer akan dinonaktifkan ketika sensor tidak mendeteksi objek

6. Penyalaan LED

Dibagian ini LED dinyalakan ketika sensor memberikan inputan ke microcontroller dan LED akan padam ketika microcontroller tidak menerima data input dari sensor.

\section{Rancangan 3D}

Untuk menggambarkan prototype pada rancangan 3D digunakan aplikasi google sketchup agar gambar yang dihasilkan terlihat lebih nyata. Adapun komponen yang digunakan pada gambar adalah dari jalur perlintasan kereta api yang menggunakan gambar seperti wujud asli. Berikut adalah gambar 3D dari aplikasi google sketchup yaitu.

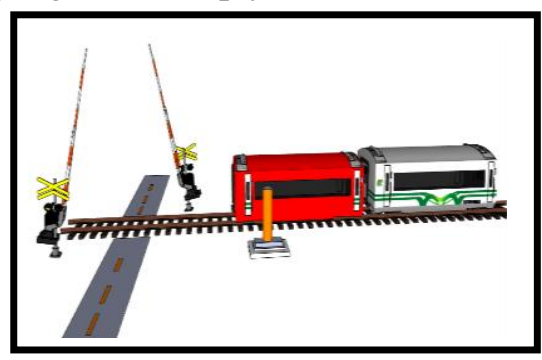

Gambar 3. Jalur Perlintasan kereta Api

Untuk mendeteksi keberadaan kereta api yang melintas dengan menggunakan sensor jarak. Berikuta adalah gambara dari samping dan tiang sensor.

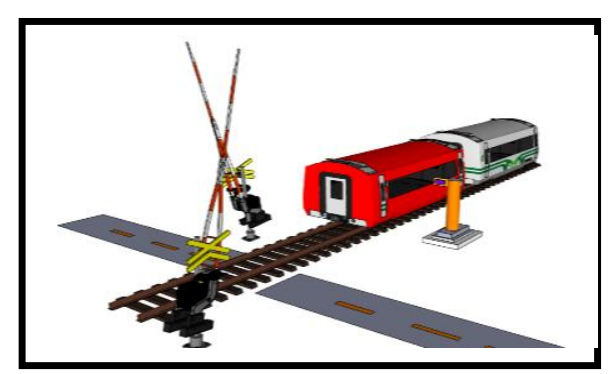

Gambar 4. Gambar Tiang Sensor

\section{Rancangan Elektronika}

Sensor yang digunakan adalah sensor Ultrasonic. Sensor Ultrasonic bertugas memberikan data input kepada Arduino Uno. Sensor Ultrasonic memiliki 4 kaki pin yang akan dihubungkan ke port Arduino Uno. Kaki pin pertama yaitu pin trigger yang dihubungkan ke port 11 (P.11) Arduino Uno, yang kedua yaitu pin echo yang akan dihubungkan ke port 12 (P.12) Arduino Uno, yang ketiga pin vec yang dihubungkan ke port vcc Arduino Uno, dan yang keempat pin ground yang akan dihubungkan ke pin gnd Arduino Uno. Berikut ini adalah gambar rangkaian Ultrasonic dan Arduino Unonya.

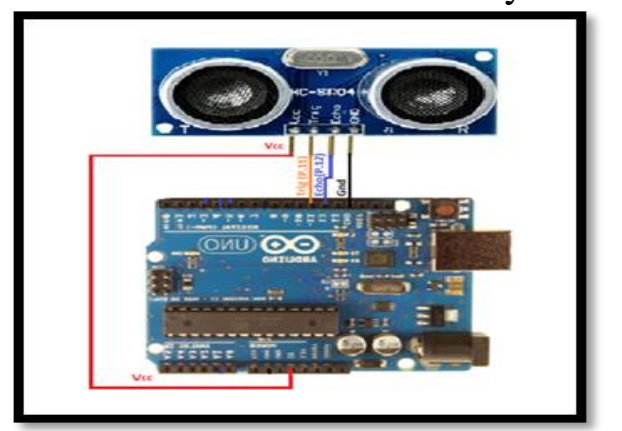

Gambar 5. Rangkaian Ultrasonic Dan Arduino Uno 
Available online at http://jurnal.goretanpena.com/index.php/JSSR

\section{Rangkaian Buzzer Dan Arduino Uno}

Buzzer digunakan sebagai pengingat pesan yang mengeluarkan tanda suara atau bunyi yang biasa disebut dengan alarm. Buzzer memiliki 2 kaki pin. Kaki pin output Buzzer dihubungkan ke port output 3 (P.3) Arduino Uno dan kaki pin ground Buzzer dihubungkan ke pin gnd Arduino Uno. Berikut ini adalah gambar rangkain Buzzer dengan Arduino Unonya.

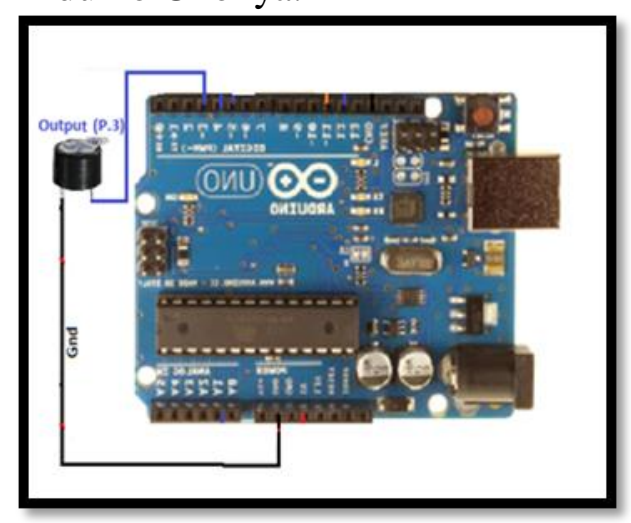

Gambar 6. Rangkaian Buzzer Dan Arduino Uno

\section{Rangkaian Motor Servo Dan Arduino Uno}

Dalam perancang pintu otomatis ini menggunakan 2 unit Motor Servo untuk membuka dan menutup pintu kereta api otomatis tersebut. Motor Servo memiliki 3 kaki pin yaitu kaki pin output, kaki pin vec dan kaki pin ground. Pada Motor Servo pertama, kaki pin output dihubungkan ke port output 4 (P.4) Arduino Uno, kaki pin vcc ke port vec Arduino Uno, dan kaki pin ground ke port ground Arduino Uno. Pada Motor Servo kedua, kaki pin output dihubungkan ke port output 5 (P.5) Arduino Uno, kaki pin vec ke port vec Arduino Uno, dan kaki pin ground ke port ground
Arduino Uno. Dibawah ini adalah gambar dari rangkaiannya.

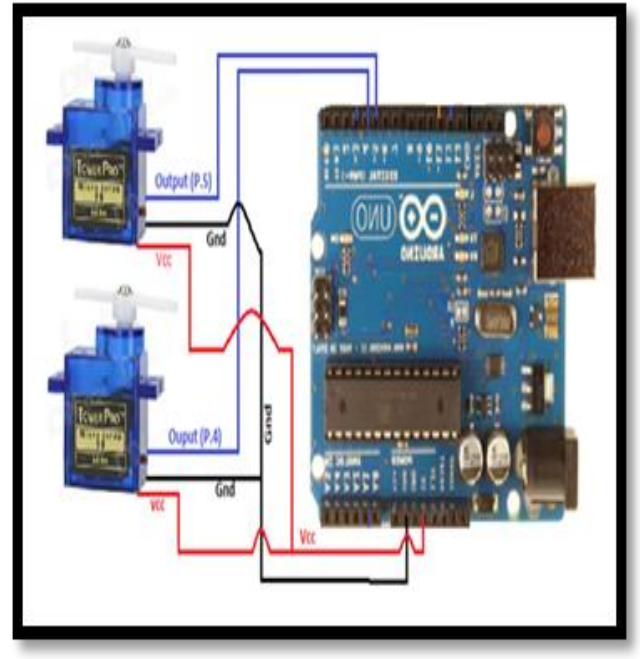

Gambar 7. Rangkaian Motor Servo Dan Arduino Uno

\section{Rangkaian LED Dan Arduino Uno}

LED digunakan untuk

memberi tanda bahwa ketika kereta api mau mendekati pintu kereta api maka LED akan menyala. Dan LED yang digunakan sebanyak 4 LED. LED memiliki 2 kaki pin yaitu kaki pin output yang dihubungkan ke port output Arduino Uno dan kaki pin ground yang dihubungkan ke port gnd Arduino Uno. LED 1 dihubungkan ke port output 6 (P.6), LED 2 dihubungkan ke port output 7 (P.7), LED 3 dihubungkan ke port output 8 (P.8), LED 4 dihubungkan ke port output 9 (P.9). Sebelum 4 LED ini dihubungkan ke port output Arduino Uno, 4 LED ini harus diberi resistor 100 ohm untuk hambatan listriknya agar LED mendapatkan tegangan listrik yang tidak melewati kapasitas tegangan inputnya. Di bawah ini adalah gambar rangkaiannya. 
Available online at http://jurnal.goretanpena.com/index.php/JSSR

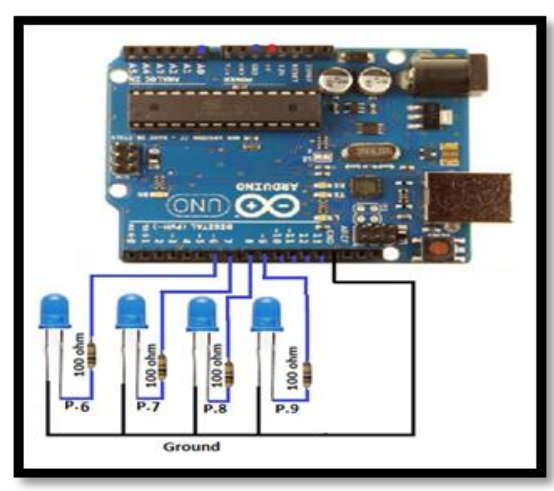

Gambar 8. Rangkaian LED Dan Arduino Uno

\section{Rangkaian Keseluruhan Komponen}

Adapun rangkaian keseluruhan pintu otomatis kereta api tersebut adalah sebagai berikut.

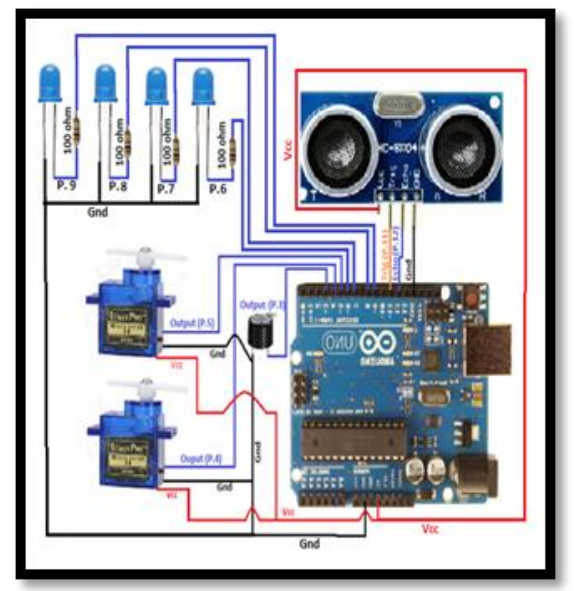

Gambar 9. Rangkaian Keseluruhan Komponen

\section{HASIL DAN PEMBAHASAN}

Dalam hal ini akan dijelaskan pengujian cara kerja dari sistem yang sudah dirancang. Rancangan berupa simulasi pintu kereta api otomatis berbasis arduino uno.

\section{Proses Pengaktifan Sistem}

Pada sistem ini pengaktifan dimulai dari menghubungkan arduino uno dengan sumber daya adaptor bertegangan 5 Volt, proses adalah dengan memasangkan jack adaptor ke arduino uno.

\section{Proses Keadaan Awal Pada Sistem}

Proses ini merupakan keadaan awal setelah sistem terhubung dengan sumber daya listrik. Pada sistem tersebut, lampu LED indikator pada arduino uno akan menyala dan sistem tersebut siap digunakan. Keadaan awal pada pintu kereta api otomatis ketika tidak ada kereta api yang melintas maka palang pintu kereta api terbuka, buzzer tidak aktif, lampu LED hijau menyala, dan sensor ultrasonic belum mendeteksi kereta api. Apabila ada kereta api yang akan melintas, sensor ultrasonic mendeteksi kereta api maka palang pintu kereta api tertutup, buzzer aktif, dan lampu LED merah nyala otomatis. Berikut ini adalah tampilan keadaan awal pada pintu kereta api otomatis berbasis arduino uno.

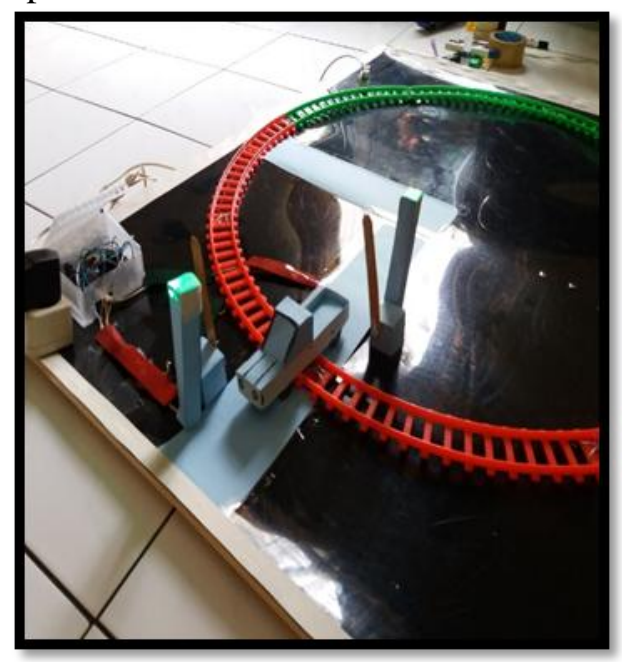

Gambar 10. Proses Keadaan Awal Pada Saat Sistem Diaktifkan

\section{Proses Sensor Ultrasonic Identifikasi Objek}

Pada proses sensor ultrasonic identifikasi objek merupakan tahapan yang dilakukan sistem untuk mendapatkan input yang kemudian akan diproses menjadi output sesuai dengan ketentuan yang sudah diterapkan. Pada pintu kereta api otomatis yang dibuat, setiap kereta api yang terdeteksi sensor 
Available online at http://jurnal.goretanpena.com/index.php/JSSR

ultrasonic maka motor servo akan bergerak menutup palang pintu kereta api, buzzer akan aktif dan lampu LED merah menyala. Berikut ini adalah gambar kereta api terdeteksi sensor.

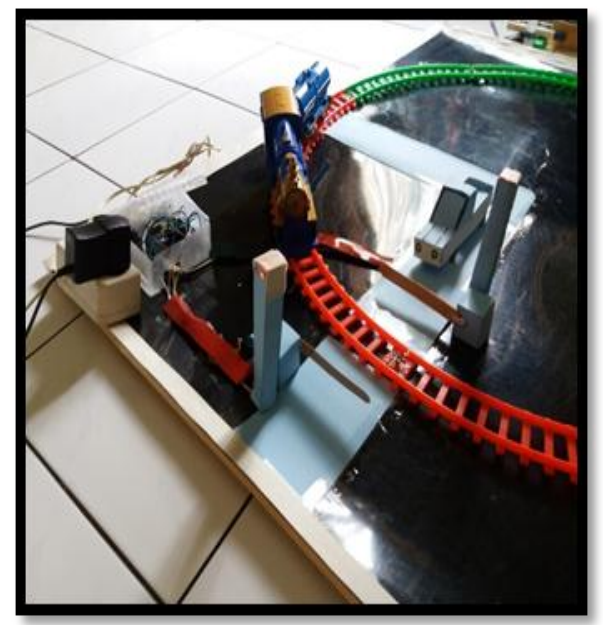

Gambar 11. Kereta Api Terdeteksi Sensor Ultrasonic

Dari beberapa kali pengujian yang dilakukan dalam simulasi pintu perlintasan kereta api dapat dilihat pada tabel dibawah ini

Tabel 1. Pengujian Sistem Keretea Api

\begin{tabular}{|c|c|c|c|c|}
\hline $\begin{array}{c}\text { Peng } \\
\text { ujian }\end{array}$ & Sensor & $\begin{array}{c}\text { Buzze } \\
\mathbf{r}\end{array}$ & LED & Servo \\
\hline 1 & $\begin{array}{c}\text { Terdeteks } \\
\text { i Objek }\end{array}$ & On & $\begin{array}{c}\text { Mera } \\
\text { h }\end{array}$ & $\begin{array}{c}\text { Tertut } \\
\text { up }\end{array}$ \\
\hline 2 & $\begin{array}{c}\text { Tidak } \\
\text { Terdeteks } \\
\text { i Objek }\end{array}$ & OFF & Hijau & $\begin{array}{c}\text { Terbu } \\
\text { ka }\end{array}$ \\
\hline
\end{tabular}

Dapat Dilihat pada tabel diatas hasil pengujian yang dilakukan menunjukkan bahawsannya jika objek terdeteksi oleh sensor maka secara otomatis akan menutup pintu portal perlintasan jalur kereta api dan secara otomatis lampu LED akan berubah menjadi merah serta buzzer hidup untuk memberitahukan kepada pengguna perlintasan agar berhati - hati karena kerata api sedang lewat dan menghindarkan resiko terjadinya kecelakan yang berakitabat fatal.

\section{SIMPULAN}

Setelah dilakukan pengujian maka hasil perancangan pintu otomatis kereta api dapat diketahui, baik kelebihannya maupun kelemahannya. Hasil analisa juga menunjukkan beberapa kelebihan dan kekurangan secara menyeluruh maupun berdasarkan komponen - komponen sistem. Perancangan pintu otomatis kereta api ini memiliki beberapa kelebihan sistem yang menjadi tolak ukur tersendiri, berikut ini adalah kelebihan sistem yang dimiliki :

1. Dapat membuka dan menutup palang pintu kereta api secara otomatis yang sesuai panjangnya kereta aga

2. Dengan mengunakan software Arduino Uno IDE, kita bisa langsung memonitor inputan objek yang dideteksi oleh sensor ultrasonic melalui menu serial monitor yang sudah disediakan oleh software arduino uno IDE tersebut tanpa harus merakit lagi komponen LCD untuk memonitoring.

3. Dengan hanya menggunakan sensor ultrasonic bisa menggerakan 2 palang pintu kereta api.

\section{DAFTAR PUSTAKA}

Asfiati, Sri Mutiara, D. T. (2020). Progress in Civil Engineering Journal UMUM ( Studi Kasus Perlintasan Kereta Api Di Jalan Padang, Bantan Timur, Kecamatan Medan Tembung ). 2(1), 31-41.

Malinowski, P. E., Georgitzikis, E., Maes, J., Vamvaka, I., Frazzica, F., Van Olmen, J., De Moor, P., Heremans, P., Hens, Z., \& Cheyns, D. (2017). Thin-film quantum dot photodiode for monolithic infrared image sensors. Sensors (Switzerland), 17(12).

https://doi.org/10.3390/s17122867

Mubarok, A., Sofyan, I., Rismayadi, A. A., \& Najiyah, I. (2018). Sistem 
Journal of Science and Social Research

ISSN $2615-4307$ (Print)

June 2021, IV (2): 147 -154

ISSN 2615 - 3262 (Online)

Available online at http://jurnal.goretanpena.com/index.php/JSSR

Keamanan Rumah Menggunakan RFID, Sensor PIR dan Modul GSM Berbasis Mikrokontroler. Jurnal Informatika, 5(1), 137-144. https://doi.org/10.31311/ji.v5i1.2734

Sadi, S. (2015). Rancang Bangun Sistem Eskalator Otomatis Menggunakan Sensor Photodioda Dan Infrared (Ir) Berbasis Mikrokontroler Atmega32.
Jurnal Dinamika UMT, l(1), 71. https://doi.org/10.31000/dinamika.v $1 \mathrm{i} 1.511$ 